\title{
Using Apparent Activation Energy as a Reactivity Criterion for Biomass Pyrolysis
}

\author{
Marion Carrier, ${ }^{* \dagger}{ }^{\dagger}$ Lidia Auret, ${ }^{\ddagger}$ Anthony Bridgwater, ${ }^{\dagger}$ and Johannes H. Knoetze $\mathrm{e}^{\ddagger}$ \\ ${ }^{\dagger}$ Bioenergy Research Group, European Bioenergy Research Institute (EBRI), Aston University, Birmingham B4 7ET, United \\ Kingdom \\ ${ }^{\ddagger}$ Process Engineering, Stellenbosch University, Private Bag X1, Matieland, 7602 Stellenbosch, South Africa
}

Supporting Information

\begin{abstract}
The reactivity of chemically isolated lignocellulosic blocks, namely, $\alpha$-cellulose, holocellulose, and lignin, has been rationalized on the basis of the dependence of the effective activation energy $\left(E_{\alpha}\right)$ upon conversion $(\alpha)$ determined via the popular isoconversional kinetic analysis, Friedman's method. First of all, a detailed procedure for the thermogravimetric data preparation, kinetic calculation, and uncertainty estimation was implemented. Resulting $E_{\alpha}$ dependencies obtained for the slow pyrolysis of the extractive-free Eucalyptus grandis isolated $\alpha$-cellulose and holocellulose remained constant for $0.05<\alpha<0.80$ and equal to $173 \pm 10,208 \pm 11$, and $197 \pm 118 \mathrm{~kJ} / \mathrm{mol}$, thus confirming the single-step nature of pyrolysis. On the other hand, large and significant variations in $E_{\alpha}$ with $\alpha$ from $174 \pm 10$ to $322 \pm 11 \mathrm{~kJ} / \mathrm{mol}$ in the region of 0.05 and 0.79 were obtained for the Klason lignin and reported for the first time. The non-monotonic nature of weight loss at low and high conversions had a direct consequence on the confidence levels of $E_{\alpha}$. The new experimental and calculation guidelines applied led to more accurate estimates of $E_{\alpha}$ values than those reported earlier. The increasing $E_{\alpha}$ dependency trend confirms that lignin is converted into a thermally more stable carbonaceous material.
\end{abstract}

\section{INTRODUCTION}

The knowledge of the complex thermal behavior of plant biomass is a key element in enabling the industrial application of processes that convert biomass efficiently into fuels or valuable chemicals. It is crucial to understand the role played by the different main components of the biomass (i.e., hemicelluloses, cellulose, and lignin) in the degradation process because their chemical reactivity is substantially different. Providing relevant macroscopic kinetics information on pyrolysis is a challenge considering the heterogeneity of biomass substrates and the number of experimental kinetic techniques, fundamental rate equations, and degradation models.

Since the early 20th century, thermal analysis techniques have been increasingly used to measure physical and chemical changes of solids/liquids as a function of the temperature/time in controlled conditions. In particular, the commonly used thermogravimetric analysis (TGA) that measures mass changes of materials is seen as a useful tool to determine the kinetic parameters of solid-state reactions. A considerable number of methods capable of quantitatively characterizing these reactions have been developed over the years and are generally categorized as model-fitting and model-free methods. In this study, we have chosen to use the classical differential isoconversional analysis, named Friedman's method, to evaluate the activation energy dependency as a function of the conversion degree without any previous knowledge of the reaction model. ${ }^{2}$

Although many concerns and issues were raised on the aptitude of isoconversional differential methods in determining reliable kinetic parameters (because of their high sensitivity toward data noise ${ }^{3}$ ), the analysis of $\mathrm{E}_{\alpha}$ dependency using these approaches has been proven to be helpful in exploring mechanisms and prediction of kinetics for synthetic polymers. ${ }^{2,4}$ The interpretation of the dependence of activation energy values upon the conversion may provide useful mechanistic clues, such as the number of presumable reaction steps and/or important indications for model-fitting methods. ${ }^{5,6}$ For example, it has been demonstrated that the use of Friedman's method applied to deconvoluate thermogravimetric signals of three pseudo-components obtained from the whole experimental signal of the raw material could satisfactorily predict the kinetic rate of the same plant material. ${ }^{6}$ The same authors observed that the resulting apparent activation energy for these pseudo-components was consistent with values reported for model compounds ascribed as hemicelluloses, cellulose, and lignin. The pyrolysis of the raw material was modeled with good approximation by three independent reactions, whose kinetic parameters were determined using model-free Friedman's kinetic method. ${ }^{6}$

It is then not surprising that numerous attempts in modeling pyrolysis kinetics based on global reaction models or the individual contribution of model compounds have been made and often failed at describing the whole degradation process of plant biomass. ${ }^{7}$ One reason that is frequently invoked to explain these discrepancies is that a mixture of model compounds is not representative of the whole lignocellulosic structure made up by three main natural biopolymers (i.e.,

Special Issue: In Honor of Michael J. Antal

Received: April 5, 2016

Revised: $\quad$ May 21, 2016

Published: May 24, 2016 
hemicelluloses, cellulose, and lignin). Few studies have reported encouraging results when using isolated natural biocomponents. For example, Orfao et al. $^{7}$ managed to predict with a good confidence interval the solid-phase pyrolysis kinetics of lignocellulosic materials using two model compounds and an extracted lignin compound assuming a first-order reaction for the three parallel reactions, thus indicating that the accurate description of the peculiar behavior of lignin is very important to successfully model biomass pyrolysis. In a more recent study, $\mathrm{Lv}$ et al. ${ }^{8}$ isolated hemicelluloses from corn stalk and provided $E_{\alpha}$ values ranging between 211.6 and $213.3 \mathrm{~kJ} / \mathrm{mol}$ depending upon the non-isothermal methods. Gasparovie et al. ${ }^{9}$ could not describe the pyrolysis of biomass combining both $E_{\alpha}$ values, with 132.9, 175.6, and $101.0 \mathrm{~kJ} / \mathrm{mol}$ ascribed to extracted hemicelluloses, cellulose, and lignin, respectively, and applying a distribution activation energy model. Although they did not provide any details on extraction methods and chemical characteristics of biopolymers used, they attributed discrepancies to the occurrence of synergistic mechanisms between compounds that were not described. The $E_{\alpha}$ value reported for extracted lignins, which is slightly higher than typical values found in the literature, $46-110 \mathrm{~kJ} / \mathrm{mol}^{10-12}$ appeared to be still too low to be representative of the complex nature of lignin.

On the basis of these previous works, this study evaluates the aptitude of Friedman's isoconversional method to provide reliable $E_{\alpha}$ levels of chemically isolated biocomponents (i.e., $\alpha$ cellulose, holocellulose, and lignin) on which mechanistic conclusions have been drawn. To do this, conventional wet chemical methods have been used to extract the carbohydrate, cellulosic, and lignin solid fractions, which have been subsequently exposed to pyrolysis conditions. Then, a comprehensive calculation method has been implemented to determine the effective activation energy. This procedure aimed at reducing experimental and calculation artifacts during TGA data collection and their preparation and evaluating confidence limits and standard deviations related to $E_{\alpha}$. Considering the accuracy and reliability of $E_{\alpha}$ values obtained for each biocomponent, the prediction of overall and apparent $E_{\alpha}$ for biomass was attempted.

\section{MATERIALS AND METHODS}

2.1. Raw and Extracted Materials. Holocellulose, $\alpha$-cellulose, and lignin fractions were isolated from a subsample of air-dried and milled Eucalyptus grandis provided by Mondi from the Kwazulu-Natal coastline. The raw eucalyptus wood chips were ground using a SM 100 Retsch mill and sieved with an AS 200 Retsch shaker. The biomass particle size range from 250 to $425 \mu \mathrm{m}$ was used for lignocellulosic characterization. The compositional analysis was carried out according the Technical Association of the Pulp and Paper Industry (TAPPI) standard methods for characterizing woody biomass. Extractives were removed using a 1:2 volume ratio of $95 \%$ ethanol and cyclohexane (instead of benzene as prescribed in the standard method T264 om88 ), followed by distilled water extraction. Klason lignin was extracted using an adapted standard method T222 om-88. ${ }^{13}$ A first hydrolysis of the biomass with $72 \%$ sulfuric acid was followed by a second hydrolysis with $3 \% \mathrm{H}_{2} \mathrm{SO}_{4}$ for $1 \mathrm{~h}$ in an autoclave at 1.25 bar and 122 ${ }^{\circ} \mathrm{C}$. The holocellulose fraction was prepared following Browning's extraction method. ${ }^{14}$ Extraction of holocellulose was achieved by adding extracted biomass $(5 \mathrm{~g})$ to demineralized water at $70-80{ }^{\circ} \mathrm{C}$ $(160 \mathrm{~mL})$, glacial acetic acid $(0.5 \mathrm{~mL})$, and sodium chlorite $(1.5 \mathrm{~g})$ with stirring, followed by two more additions of acetic acid and sodium chlorite at $1 \mathrm{~h}$ intervals. Once cooled $\left(10^{\circ} \mathrm{C}\right)$, the mixture was filtered. The solid residue was then washed with high-performance liquid chromatography (HPLC)-grade acetone $(50 \mathrm{~mL})$ and HPLC-grade ethanol $(100 \mathrm{~mL})$ and dried. $\alpha$-Cellulose was obtained by dissolution of the holocellulose extract $(3 \mathrm{~g})$ in a $17.5 \%(\mathrm{w} / \mathrm{w})$ sodium hydroxide solution $(35 \mathrm{~mL})$ under stirring at $20{ }^{\circ} \mathrm{C}$, followed by three additions of $\mathrm{NaOH}$ solution (in total $45 \mathrm{~mL}$ ) at $10 \mathrm{~min}$ intervals. The residue was washed with a $10 \%$ acetic acid solution $(40 \mathrm{~mL})$ and distilled water and finally filtered. Both fractions were determined from the weight ratio of the solid residue after extraction and drying $\left(105^{\circ} \mathrm{C}\right)$. All isolated materials were stored in sealed glass flasks. The resulting lignocellulosic composition was $2.6( \pm 0.2) \mathrm{wt} \%$ [on a dry and ash-free basis (daf)] extractives, $82.2( \pm 2.4)$ wt \% (daf) holocellulose, 57.5 $( \pm 0.3)$ wt $\%$ (daf) $\alpha$-cellulose, and $15.2( \pm 1.5)$ wt $\%$ (daf) lignin. ${ }^{15}$

2.2. Ultimate and Proximate Analyses. Proximate analysis was determined in accordance with the ASTM E1131 standard procedure using a TGA/DSC 1-LF1100 Mettler Toledo. Ultimate analysis was performed using a TruSpec Micro from LECO in accordance with ASTM D5291-10. The calibration of $\mathrm{C}, \mathrm{H}, \mathrm{N}$, and $\mathrm{S}$ contents was performed using the standard sulfamethazine (QC, LECO), and the results were expressed on a dry basis.

2.3. TGA: Collection of Data. TGAs were conducted using a TGA/DSC 1 (LF 1100) unit (Mettler Toledo) thermogravimetric analyzer. For all TGA experiments, a nitrogen flow rate of $20 \mathrm{~mL} / \mathrm{min}$ was used as protective gas, while $50 \mathrm{~mL} / \mathrm{min}$ was used as reactive gas. A constant sample size of $15 \mathrm{mg}$ was placed in a $70 \mu \mathrm{L}$ alumina crucible. These samples were heated from 313 to $873 \mathrm{~K}$ using slow reactor heating rates $\left(10,20,30\right.$, and $\left.50{ }^{\circ} \mathrm{C} / \mathrm{min}\right)$. To minimize systematic errors in the temperature measurement that may have a large impact on the final values of kinetic parameters if not corrected, ${ }^{16}$ two thermocouples (i.e., oven and sample thermocouples) were used and calibrated using three different pure metals (indium, aluminum, and gold) provided by Mettler Toledo. Resulting onset temperatures for both standards were $156.4{ }^{\circ} \mathrm{C}$ for In, $659.4{ }^{\circ} \mathrm{C}$ for $\mathrm{Al}$, and 1063.3 ${ }^{\circ} \mathrm{C}$ for $\mathrm{Au}$. When past recommendations on good thermal analysis practices provided by Burnham and Braun ${ }^{17}$ and more recent recommendations provided by the ICTAC Kinetics Committee ${ }^{18}$ are taken into account, a blank correction was applied to each TGA curve. Indeed, integral TGA data sets obtained under the conditions of continuous heating require a baseline correction for the buoyancy effect that reveals itself as an apparent mass gain.

2.4. Kinetic Method and Procedure. As clearly demonstrated by Arnold et al. ${ }^{19}$ and more recently by White et al., ${ }^{1}$ the recurrent inconsistency of $E_{\alpha}$ values found in the literature is primarily influenced by the experimental conditions but also by the choice of the kinetic method, thus making the comparison to values from the literature difficult. The non-isothermal isoconversional method, Friedman's method, has been selected in this study for the main reasons mentioned earlier in the Introduction. Non-isothermal and heterogeneous solid-state reactions are in general described by the following equation:

$$
\frac{\mathrm{d} \alpha}{\mathrm{d} t}=A \exp \left(-\frac{E}{R T}\right) f(\alpha)
$$

with

$$
\alpha=\frac{m_{0}-m_{i}}{m_{0}-m_{\mathrm{f}}}
$$

and

$$
\mathrm{d} t=\frac{\mathrm{d} T}{\beta}
$$

where $\alpha$ is the extent of the conversion, $t$ is the time, $A$ is the preexponential factor, $E_{\alpha}$ is the activation energy, $R$ is the gas constant, $T$ is the temperature, $f(\alpha)$ is the reaction model, $m_{0}$ is the initial mass of reactant, $m_{i}$ is its mass at a certain time during the reaction, $m_{\mathrm{f}}$ is the final mass at the end of reaction, and $\beta$ stands for the heating rate. The actual transformation of eq 1 that consists of replacing the temporal differential by eq 3 under non-isothermal conditions may have important implications when step reaction kinetics are studied, and we must "abandon the notion that a single activation energy controls the temperature dependence of the reaction rate throughout the entire 
DATA PREPARATION

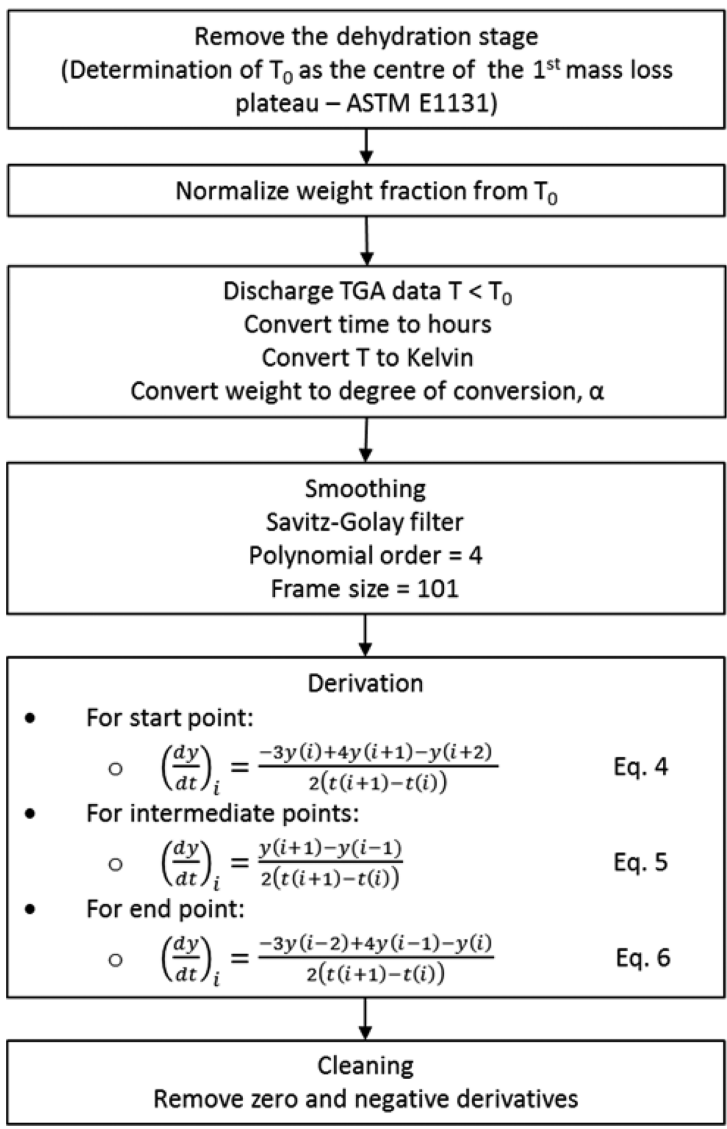

KINETIC CALCULATION

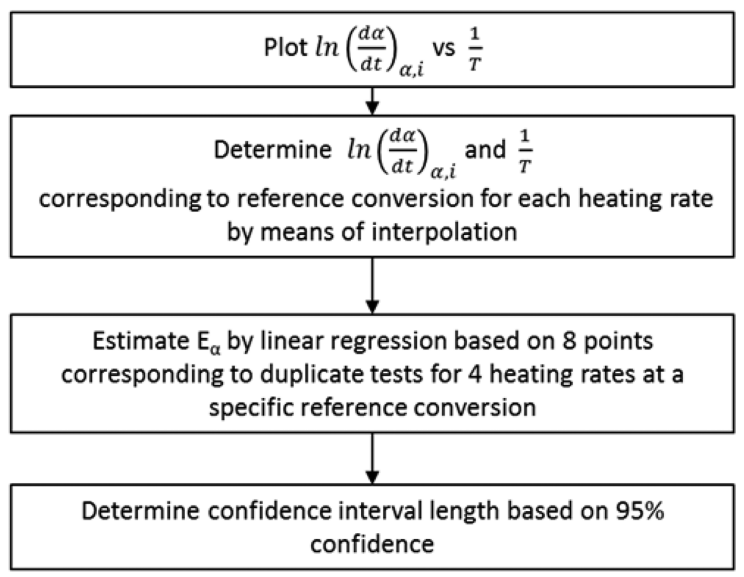

Figure 1. Step-by-step flow diagrams for data preparation and kinetic calculation.

duration of a solid state reaction" as stated by Vyazovkin and Wight. ${ }^{20}$ Once again, on the basis of past recommendations, ${ }^{17,18}$ an automated and rigorous methodology to determine kinetic parameters was implemented using MATLAB (R2015a, version 8.5.0). The main actions that were undertaken are summarized by the flow diagram (Figure 1) and separated in two main stages: data preparation and kinetic calculation.

2.4.1. Data Preparation. In the first place, the dehydration stage that is clearly separated from the overall pyrolysis stage under slow pyrolysis (Figure 2) was removed considering the ASTM E1131 method, which recommends the center of the first mass loss plateau as

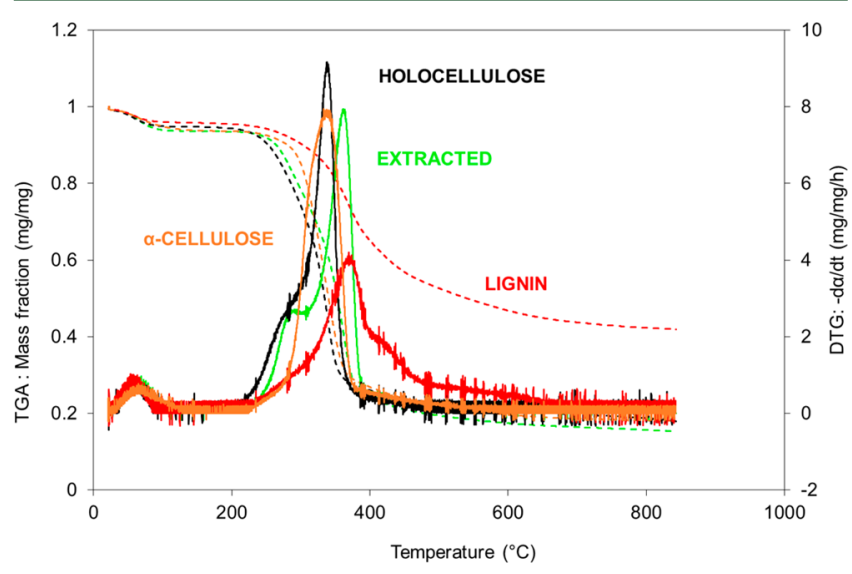

Figure 2. Thermogravimetric (TGA) and derivative (DTG) curves for extracted E. grandis, holocellulose, $\alpha$-cellulose, and lignin at $10{ }^{\circ} \mathrm{C} /$ $\min$. the end of the dehydration stage. The selected average temperatures for each run are shown in Supplementary Table 1 of the Supporting Information. The weight data sets were normalized on the initial mass at this average temperature, and the extent of reaction was expressed by eq 2 .

Smoothing of the data was applied before their derivation (Figure 2) because differentiating integral data tends to magnify noise, ${ }^{21}$ which can lead to systematic calculation errors and, thus, affect the confidence interval of $E_{\alpha}$. This can be avoided by smoothing the data before their derivation ${ }^{22}$ but also using a reasonable amount of weight loss measurements for small time intervals and, thus, by making $\mathrm{d} \alpha$ (eq 1) infinitesimal, which is an important prerequisite for applying Friedman's method. ${ }^{23,24}$ A decreasing data collection interval of 0.6 , $0.4,0.3$, and $0.2 \mathrm{~s}$ was set for increasing reactor heating rates of 10,20 , 30 , and $50{ }^{\circ} \mathrm{C} / \mathrm{min}$, respectively. Nevertheless, it is important to mention that selecting small data collection rates $(0.2-0.6 \mathrm{~s})$ may increase experimental noise as a result of the non-monotonic loss in weight during the reaction. The method by Savitzky and Golay was applied to smooth data. This latter was found superior to the adjacent averaging method because it uses a polynomial of high order to describe curves. ${ }^{22}$ Once filtered, the data were derived using eqs 4 and 6 and eq 5 (Figure 1) to determine boundaries and intermediate points. Finally, a last cleaning/filtering stage consisting of the removal of negative calculated derivatives and null calculated derivatives was included.

2.4.2. Kinetic Calculation. Friedman's analysis based on the Arrhenius equation applies the logarithm of the conversion rate $\mathrm{d} \alpha$ / $\mathrm{d} t$ (eq 1) as a function of the reciprocal temperature at different degrees of the conversion $\alpha$ as follows:

$$
\ln \left(\frac{\mathrm{d} \alpha}{\mathrm{d} t}\right)_{\alpha, i}=\ln \left[A_{\alpha} f(\alpha)\right]-\frac{E_{\alpha}}{R T_{\alpha, i}}
$$



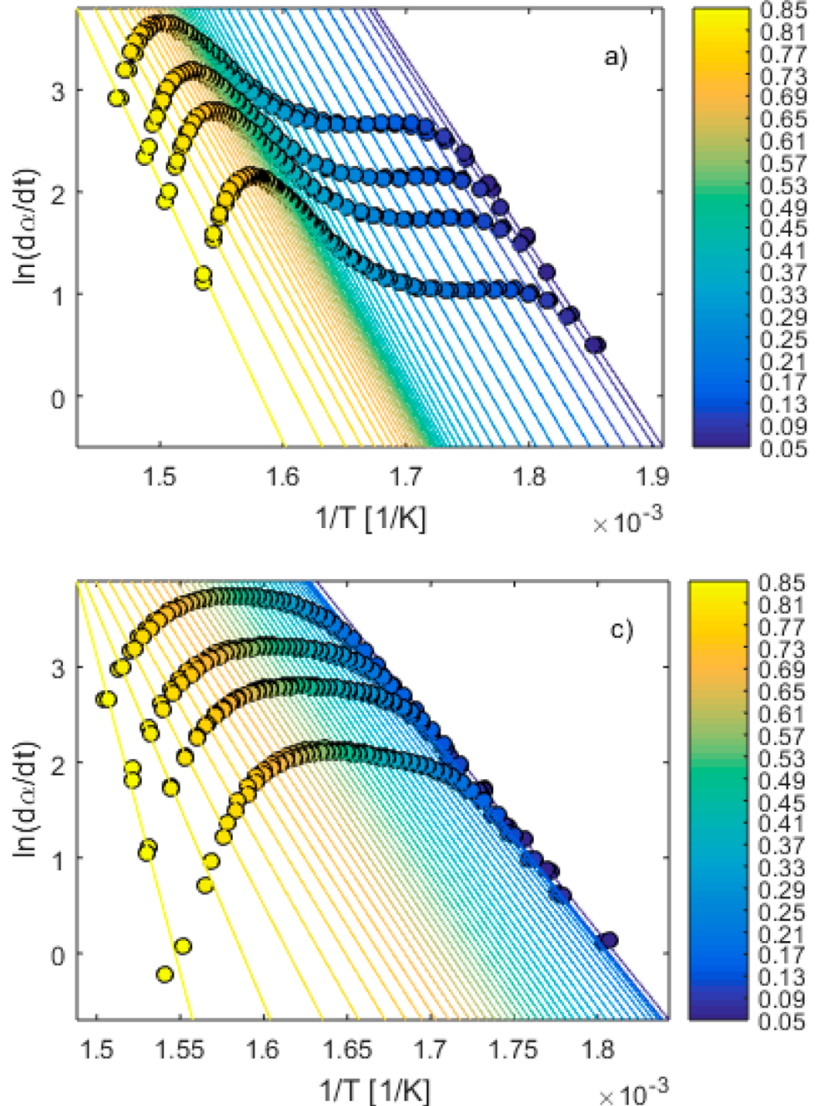
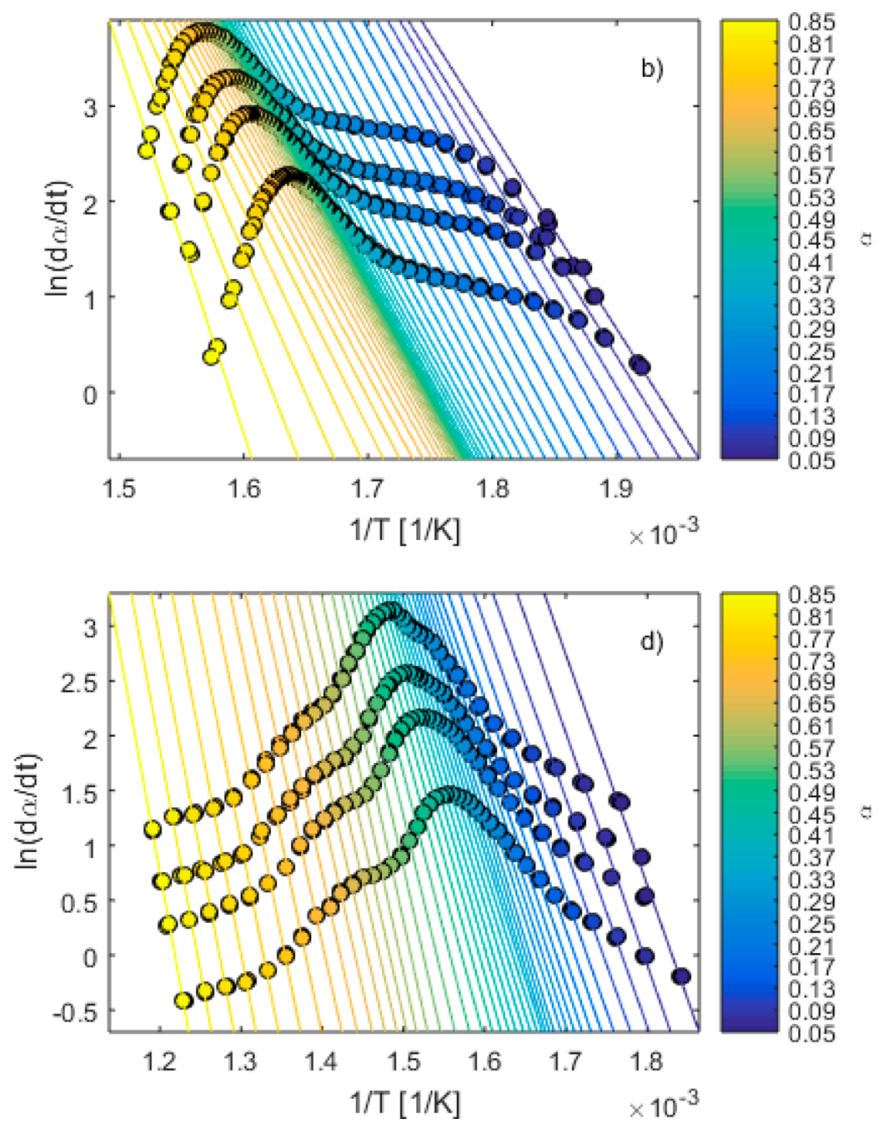

Figure 3. Arrhenius plot for the (a) extracted material, (b) holocellulose, (c) $\alpha$-cellulose, and (d) lignin.

Table 1. Ultimate and Proximate Analyses of the Materials

\begin{tabular}{|c|c|c|c|c|c|}
\hline & raw & extracted & $\alpha$-cellulose & holocellulose & lignin \\
\hline $\mathrm{MC}^{a}$ & 6.2 & 6 & 4.6 & 5.8 & 4.2 \\
\hline \multicolumn{6}{|c|}{ Ultimate Analysis (Dry, wt \%) ${ }^{a}$} \\
\hline $\mathrm{C}$ & $48.67 \pm 0.23$ & $49.29 \pm 0.08$ & $43.97 \pm 0.07$ & $45.64 \pm 0.0$ & $60.90 \pm 0.81$ \\
\hline $\mathrm{H}$ & $6.10 \pm 0.04$ & $6.32 \pm 0.03$ & $6.44 \pm 0.07$ & $6.02 \pm 0.06$ & $5.59 \pm 0.13$ \\
\hline $\mathrm{N}$ & $0.09 \pm 0.01$ & $0.08 \pm 0.01$ & $0.01 \pm 0.00$ & $0.10 \pm 0.10$ & $0.14 \pm 0.01$ \\
\hline$S$ & $0.66 \pm 0.14$ & $0.47 \pm 0.15$ & $0.51 \pm 0.07$ & $0.35 \pm 0.5$ & $0.78 \pm 0.01$ \\
\hline $\mathrm{O}$ & $43.95 \pm 0.12$ & $43.67 \pm 0.19$ & $48.35 \pm 0.21$ & $46.51 \pm 0.34$ & $30.72 \pm 0.96$ \\
\hline \multicolumn{6}{|c|}{ Proximate Analysis (Dry, wt $\%)^{b}$} \\
\hline VM & 86.25 & 85.36 & 85.97 & 83.40 & 57.28 \\
\hline $\mathrm{FC}$ & 20.36 & 14.47 & 13.42 & 15.53 & 41.04 \\
\hline $\mathrm{AC}$ & 0.53 & 0.17 & 0.71 & 1.39 & 1.88 \\
\hline
\end{tabular}

${ }^{a}$ Determined by ASTM D5291-10. ${ }^{b}$ Determined by ASTM E113.

Because $f(\alpha)$ is constant at each conversion degree $\alpha_{i}$, the method is named "isoconversional". Once $\ln (\mathrm{d} \alpha / \mathrm{d} t)$ versus $1 / T$ was plotted, an interpolation procedure was then applied to determine isoconversional couple points $[1 / T$ and $\ln (\mathrm{d} \alpha / \mathrm{d} t)]$, where the experiments at different heating rates would correspond to the same degree of conversion. A first approximation to robust (local) linear interpolation, addressing some of the experimental issues (for example, a small sample interval may lead to the recording of the same values of consecutive weight fractions, and/or the presence of noise causes dependent variables to be non-monotonic) has been applied. The natural ordering of the weight fraction data was considered as informative, i.e., descending order from 1 (this follows time progression as well). This interpolation procedure is fully described in Supplementary Information 2 of the Supporting Information, with Supplementary Figure 2 of the Supporting Information displaying the interpolated values.

The linear dependence of the logarithm of the reaction rate over $1 /$ $T$ as illustrated by the Arrhenius plots (Figure 3) allows for the determination of the kinetic parameters, $E_{\alpha}$ and $A$, with the slope of $E_{\alpha} / R$ and the intercept $A$. After interpolation, $E_{\alpha} / R$ was estimated by linear regression for every four heating rate points combining two different data sets at a specific extent of conversion based on eq 7 .

Finally, the confidence intervals and standard deviations for $E_{\alpha}$ were determined according to the traditional linear regression standard error approach.

\section{RESULTS AND DISCUSSION}

3.1. Raw Thermogravimetric Results. The interpretation of derivative thermogravimetric (DTG) curves is often required as a prerequisite to extract preliminary and important thermophysical characteristics of materials. The main DTG peak is usually attributed to the cellulose degradation, accompanied by a shoulder at the lower temperature, which is related to the hemicellulose degradation, and a tail at a high 

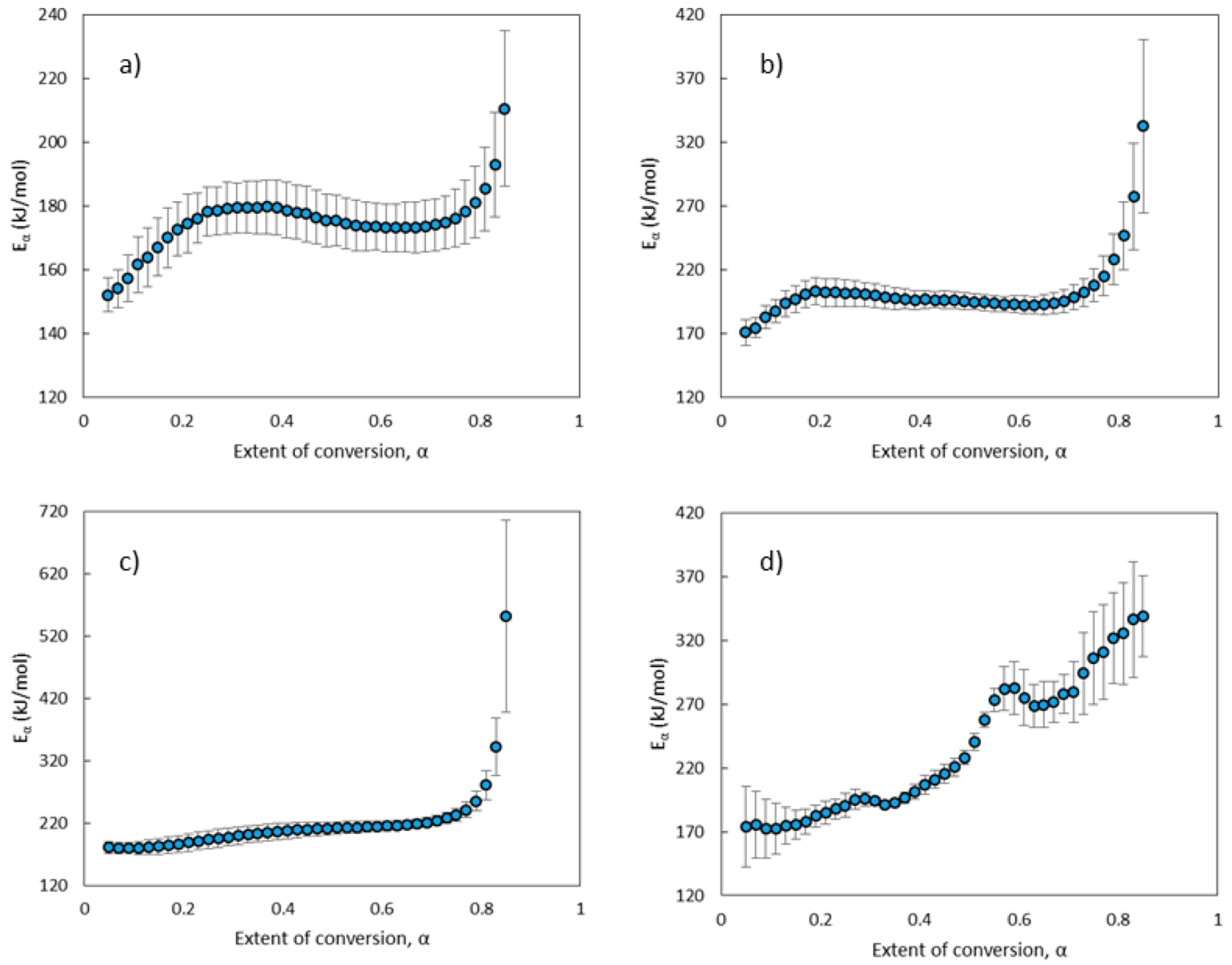

Figure 4. $E_{\alpha}$ dependency upon conversion of pyrolysis of (a) extracted biomass, (b) holocellulose, (c) $\alpha$-cellulose, and (d) lignin. Errors bars represent confidence intervals.

temperature corresponding to the lignin degradation. The shape and area of the peaks (Figure 1) follow classical trends. The presence of a larger peak located between 287 and $371{ }^{\circ} \mathrm{C}$ is in general attributed to high concentrations of $\alpha$-cellulose, while the presence of a peak in the temperature range of 200$300{ }^{\circ} \mathrm{C}$ confirms the presence of a non-negligible amount of hemicelluloses. The flat tailing section of the DTG curve is ascribed to the lignin because it is known to decompose slowly over a broad temperature range. ${ }^{25}$

The application of Friedman's method implies the use of multiple heating rate programs, thus allowing us to point out the effect of the heating rate on biomass pyrolysis. An increase of the reactor heating rate from 10 to $50{ }^{\circ} \mathrm{C} / \mathrm{min}$ led to an increase of the maximal temperature, which is usually correlated to the intrinsic thermal lag of the biomass as a result of the endothermal character of the pyrolysis reaction (Supplementary Figure 1 of the Supporting Information). The maximum rates of maximum loss were also increased. Previous studies that reported similar trends ${ }^{26,27}$ ascribed this phenomenon to mass and heat transfer limitations within the particles, which are overcome when higher heating rates are applied.

When the heating rate is increased from 10 to $50{ }^{\circ} \mathrm{C} / \mathrm{min}$, the dehydration stage shifts slowly toward the main pyrolysis peak, as confirmed by the systematic decrease of the temperature range of the first plateau (Supplementary Table 1 of the Supporting Information). This observation indicates that the physical water, ascribed as the moisture content (MC)
(Table 1) and generally residing outside the cell walls, should have a limited impact on the chemistry of slow pyrolysis and, therefore, on the associated levels of activation energy. ${ }^{28}$

3.2. $E_{\alpha}$ Dependency. The $E_{\alpha}$ dependency (Figure 4) was determined for both biopolymers isolated according to wet chemical methods described in section 2.1. The detailed evaluation of $E_{\alpha}$ versus $\alpha$ curves for $0.05<\alpha<0.79$ indicates that $E_{\alpha}$ values for the extracted material, holocellulose, and $\alpha$ cellulose correspond to unique values of $173 \pm 10,197 \pm 11$, and $208 \pm 11 \mathrm{~kJ} / \mathrm{mol}$, respectively, between conversions of 0.05 and 0.79 , while $E_{\alpha}$ values related to the lignin increase steadily and sharply from 174 to $322 \mathrm{~kJ} / \mathrm{mol}$ between 0.05 and 0.79 with increasing uncertainties for lower and higher confidence intervals (deviations up to $300 \mathrm{~kJ} / \mathrm{mol}$ when $\alpha<0.05$ and $\alpha>$ $0.80)$. A comparison to the literature is difficult because substantial variations in the apparent activation energy were reported for the same type of biomass by White et al. ${ }^{1}$ They mentioned that multiple causes (e.g., experimental and calculation system errors, thermal lag, temperature gradient, compensation effect, etc.) are at the origin of these variations and led to major confusion in the interpretation of biomass pyrolysis kinetics. Despite this confusion, a consistent pattern for the biomass decomposition process is often observed and generally described by global reactions, including the degradation of three pseudo-components, with typical activation energies of $55-187 \mathrm{~kJ} / \mathrm{mol}$ for the first pseudocomponent (corresponding to hemicelluloses), $)^{7,11,30-32} 195-$ 

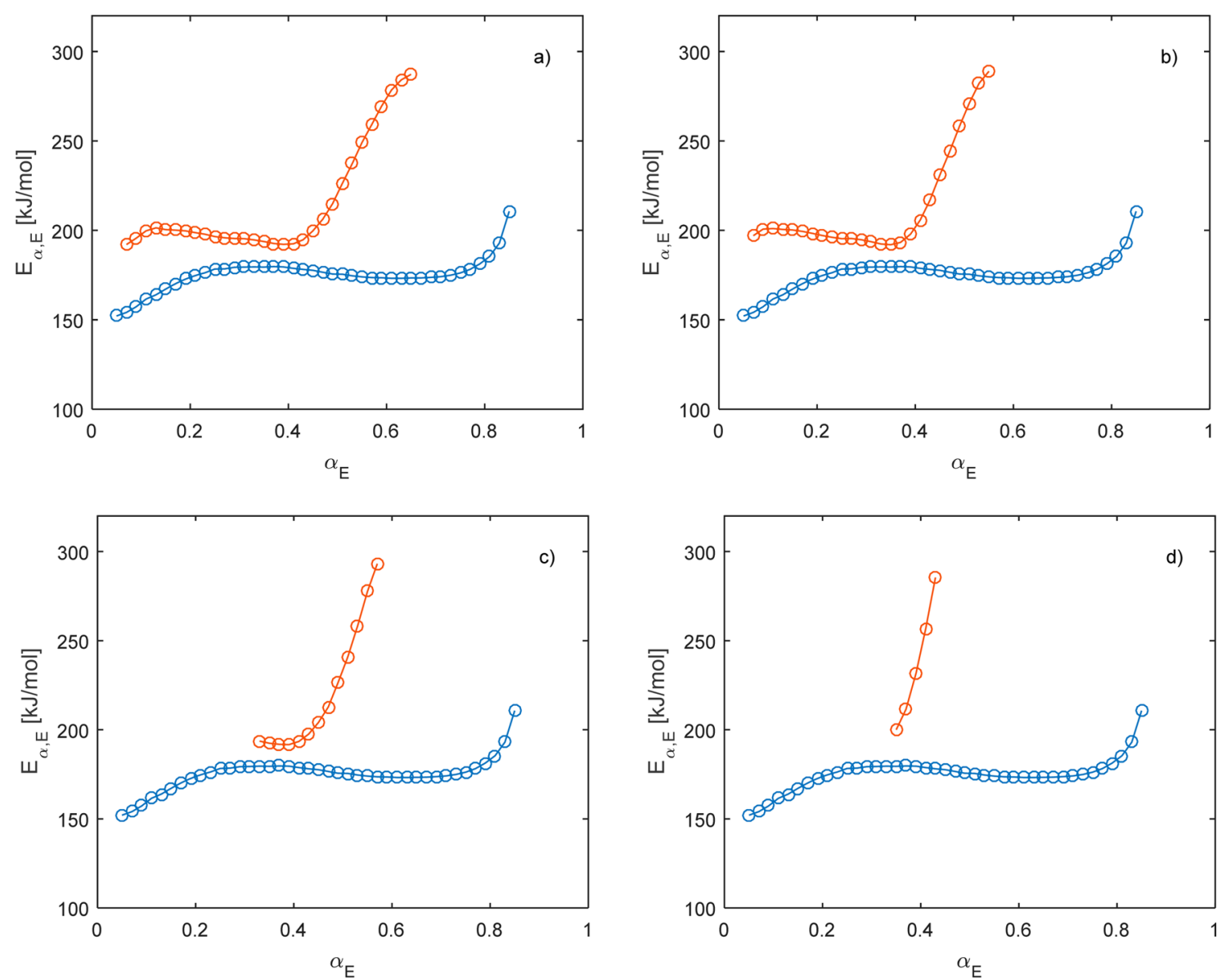

Figure 5. Comparison of actual (blue) and predicted (orange) $E_{\alpha}$ dependencies at (a and b) $10{ }^{\circ} \mathrm{C} / \mathrm{min}$ as duplicates and (c and d) $50{ }^{\circ} \mathrm{C} / \mathrm{min}$ as duplicates.

$236 \mathrm{~kJ} / \mathrm{mol}$ for the second pseudo-component (cellulose), ${ }^{5,11,31,32}$ and $35-267 \mathrm{~kJ} / \mathrm{mol}$ for the third and last pseudo-component (lignin). ${ }^{10,11,31-33}$ On the other hand, the reactivity of the holocellulose fraction that contains both carbohydrates has received less attention. $E_{\alpha}$ of this latter was found equal to $182 \mathrm{~kJ} / \mathrm{mol} .{ }^{10}$ Finally, Antal et al. ${ }^{34}$ concluded that the pyrolysis of a small sample of pure cellulose is characterized by an endothermic reaction governed by a firstorder rate law with a high activation energy (ca. $238 \mathrm{~kJ} / \mathrm{mol}$ ).

There is then a good correspondence between the present and past $E_{\alpha}$ values for the slow pyrolysis of the raw biomass, extracted biomass, holocellulose, and $\alpha$-cellulose. These values remain constant throughout most of the process, which is, in general, related to the single-step nature of a reaction. Nevertheless, the range of $E_{\alpha}$ values obtained here for lignin are much higher and also increase with the extent of degradation (Figure 4), which is representative of the great variety of bonds ${ }^{29}$ and the multiphasic character of its conversion. $^{28}$ The last phenomenon can be explained by an increase in the thermal stability as a result of the increasing aromatic character of the lignin-derived char when higher temperatures are reached, turning lignin into a highly crosslinked carbonaceous material. ${ }^{35}$ If the highest and changing values obtained for lignin are more appropriate than the low and often reported literature values to describe lignin behavior, these differences could also be attributed to alterations of the chemical structure during the Klason extraction. ${ }^{36} \mathrm{~A}$ similar and increasing trend of $E_{\alpha}$ values above $\alpha=0.79$ for the extracted materials, holocellulose, and $\alpha$-cellulose was observed and ascribed to the formation of an aromatic polycyclic structure ${ }^{37}$ of a higher thermal stability. ${ }^{38}$

Greater levels of variance led to larger confidence intervals below 0.15 and above 0.6, in particular, for lignin (Figure 4), which can be explained by the non-monotonic loss of weight collected for low and higher conversions, as already reported in section 2.4.1. These disturbances can also be directly associated with the thermal behavior of lignin, namely, its melting at a low temperature and the high thermal stability of its solid residue at a higher temperature. These results suggest that alternatives to thermogravimetric techniques are required to assess the pyrolysis reaction of lignin over the whole conversion range.

3.3. Prediction of Global $E_{\alpha}$. The lack of description of synergistic mechanisms between pyrolysis products evolved from the fact that the main biopolymers does not permit the full description of global pyrolysis kinetics. With the view to quantify the potential role of these synergies and provide indices/clues to describe them, the prediction of global $E_{\alpha}$ was attempted.

Earlier work of Mamleev et al. ${ }^{5}$ showed that the overall degree of cellulose decomposition could be described as a simple additive relationship between the overall apparent activation energies and activation energies of three individual and independent processes. Assuming that the pyrolysis of the studied woody biomass can be described by two independent and parallel reactions, we obtained the following relationship based on Mamleev's approach: 


$$
E_{\alpha, i}=\frac{w_{\mathrm{H}} E_{\alpha, \mathrm{H}} \frac{\mathrm{d} \alpha_{\mathrm{H}}}{\mathrm{d} t}+w_{\mathrm{L}} E_{\alpha, \mathrm{L}} \frac{\mathrm{d} \alpha_{\mathrm{L}}}{\mathrm{d} t}}{w_{\mathrm{H}} \frac{\mathrm{d} \alpha_{\mathrm{H}}}{\mathrm{d} t}+w_{\mathrm{L}} \frac{\mathrm{d} \alpha_{\mathrm{L}}}{\mathrm{d} t}}
$$

where $E_{\alpha, i}$ stands for the activation energy of the biopolymer $i$, $\alpha_{i}$ stands for the extent of the conversion, $t$ stands for the time, and $w_{i}$ stands for the weight fraction.

In this study, the activation energy was predicted on the basis of the above-mentioned equation, which considers $E_{\alpha}$ of the extracted biomass $\left(E_{\alpha, \mathrm{E}}\right)$ as a function of the activation energy for holocellulose $\left(E_{\alpha, \mathrm{H}}\right)$ and lignin $\left(E_{\alpha, \mathrm{L}}\right)$ weighted by their respective mass ratio (i.e., $w_{\mathrm{H}}=82.2 \mathrm{wt} \%$ for the holocellulose and $w_{\mathrm{L}}=12.5 \mathrm{wt} \%$ for lignin) for each value of their respective degree of conversion $\left(\alpha_{\mathrm{H}}\right.$ or $\left.\alpha_{\mathrm{L}}\right)$ at the same $T$. The comparison of actual and predicted curves (Figure 5) indicates that the pyrolysis of the extracted biomass cannot be modeled by two independent and parallel reactions and even less likely by three independent and parallel reactions. However, it is worth noting that both trends are closely related, with an apparent delay in degradation for the predicted curve.

The aforementioned observations may indicate that, in addition to the potential alterations of the chemical structure of holocellulose and lignin that occur during the extraction treatments $^{25}$ mentioned in section 3.2, the pyrolysis rate of biomass is also conditioned by the presence of another component binding both holocellulose and lignin blocks and identified earlier as lignocellulosic-carbohydrate complexes (LCCs) defined as hybrid (carbohydrate-lignin) chemical structures. ${ }^{39}$ The consistency of $E_{\alpha}$ values between actual and predicted curves suggests that the chemical nature of the LCCs has a limited impact on biomass reactivity, while its architecture could promote temperature gradients within biomass. Moreover, these results suggest that any kinetic model should include at least three parallel reactions representing both transformations of the carbohydrate fraction, LCCs, and lignin as an alternative to the traditional pyrolysis kinetic models developed for wood. ${ }^{40,41}$

\section{CONCLUSION}

A new and comprehensive procedure to carefully examine accuracy and reliability of apparent activation energy $\left(E_{\alpha}\right)$ values for biomass pyrolysis has been developed on the basis of past recommendations. TGA combined with Friedman's kinetic approach allowed for the determination of $E_{\alpha}$ values for the chemically isolated biopolymers, $\alpha$-cellulose, holocellulose, and lignin. The $E_{\alpha}$ values reported for $\alpha$-cellulose and holocellulose were found in accordance with those found in the literature, while striking differences between $E_{\alpha}$ values for lignin pyrolysis were obtained. Although, the actual values proposed in this study are more reasonable to describe the highly functional chemical structure of lignins, it is possible that the extraction technique applied could have affected the original chemical structure of lignin, thus changing its thermal behavior and, therefore, the level of energy required for its conversion.

The trends of the $E_{\alpha}$ dependency shown have then confirmed and pointed out important mechanistic features. A set of unique $E_{\alpha}$ values is needed to describe extracted woody biomass, holocellulose, and $\alpha$-cellulose, thus indicating that one couple of kinetic parameters will suffice to model the pyrolysis of these biopolymers. On the other hand, the broad distribution of $E_{\alpha}$ values characteristic of the lignin degradation needs to be modeled by a continuous function. The presence of lignin will therefore confer a peculiar thermal behavior for the overall plant biomass, which can be clearly described as a precursor for producing highly cross-linked materials.

Finally, the attempt to predict $E_{\alpha}$ dependency for the woody biomass free of its extractives, although unsatisfactory, has allowed us to reveal clear manifestations of transfer limitations within the biomass. On the basis of these results, it can be concluded that to be representative of the unconventional biomass pyrolysis process, future and new kinetic models should therefore include reaction models accounting for both chemical and phenomenological events with the parallel conversions of the three main blocks holocellulose, lignin, and LCC and heat transfer limitations.

\section{ASSOCIATED CONTENT}

\section{S Supporting Information}

The Supporting Information is available free of charge on the ACS Publications website at DOI: 10.1021/acs.energyfuels.6b00794.

Supplementary Table 1, sample and reference temperature profiles $\left(T_{\mathrm{s}}\right.$ and $\left.T_{\mathrm{r}}\right)$ within the TGA equipment when pyrolyzing extracted biomass under 10 and $50{ }^{\circ} \mathrm{C} /$ min (Supplementary Figure 1), procedure for robust interpolation (Supplementary Information 2), and graphic representation of the interpolation result demonstrated on data set 1 (Supplementary Figure 2) (PDF)

\section{AUTHOR INFORMATION}

\section{Corresponding Author}

*E-mail: m.carrier@aston.ac.uk.

\section{Notes}

The authors declare no competing financial interest.

\section{ACKNOWLEDGMENTS}

The authors acknowledge the participation of M. Jan Erns Joubert for extracting the holocellulose and $\alpha$-cellulose materials and the European Union and Horizon 2020 to financially support the action H2020-MSCA-IF-2014, Pyrochem, Grant 656967, entitled: "Biopolymers ${ }^{13} \mathrm{C}$ Tracking during Fast Pyrolysis of Biomass-A 2-Level Mechanistic Investigation”.

\section{REFERENCES}

(1) White, J. E.; Catallo, W. J.; Legendre, B. L. Biomass pyrolysis kinetics: A comparative critical review with relevant agricultural residue case studies. J. Anal. Appl. Pyrolysis 2011, 91, 1-33.

(2) Vyazovkin, S. Model-free kinetics Staying free of multiplying entities without necessity. J. Therm. Anal. Calorim. 2006, 83, 45-51.

(3) Sbirrazzuoli, N.; Girault, Y.; Elégant, L. Simulations for evaluation of kinetic methods in differential scanning calorimetry. Part 1. Application to single-peak methods: Freeman-Carroll, Ellerstein, Achar-Brindley-Sharp and multiple linear regression methods. Thermochim. Acta 1995, 260, 147-164.

(4) Burnham, A. K.; Dinh, L. N. A comparison of isoconversional and model-fitting approaches to kinetic parameter estimation and application predictions. J. Therm. Anal. Calorim. 2007, 89 (2), 479490.

(5) Mamleev, V.; Bourbigot, S.; Le Bras, M.; Yvon, J.; Lefebvre, J. Model-free method for evaluation of activation energies in modulated thermogravimetry and analysis of cellulose decomposition. Chem. Eng. Sci. 2006, 61, 1276-1292.

(6) Aboyade, A. O.; Hugo, T. J.; Carrier, M.; Meyer, E. L.; Stahl, R.; Knoetze, J. H.; Görgens, J. H. Non-isothermal kinetic analysis of the 
devolatilization of corn cobs and sugar cane bagasse in an inert atmosphere. Thermochim. Acta 2011, 517 (1-2), 81-89.

(7) Orfao, J. J. M.; Antunes, F. J. A.; Figueiredo, J. L. Pyrolysis kinetics of lignocellulosic materials-three independent reactions model. Fuel 1999, 78, 349-358.

(8) Lv, G. J.; Shu-bin, W.; Lou, R. Kinetic study of the thermal decomposition of hemicellulose isolated from corn stalk. BioResources 2010, 5 (2), 1281-1291.

(9) Gašparoviè, L.; Labovský, J.; Markoš, J. Calculation of kinetic parameters of the thermal decomposition of wood by distributed activation energy model (DAEM). Chem. Biochem. Eng. Q. 2012, 26 (1), 45-53.

(10) Jauhiainen, J.; Conesa, J. A.; Font, R.; Martín-Gullón, I. Kinetics of the pyrolysis and combustion of olive oil solid waste. J. Anal. Appl. Pyrolysis 2004, 72 (1), 9-15.

(11) Grønli, M. G.; Varhegyi, G.; Di Blasi, C. Thermogravimetric Analysis and Devolatilization Kinetics of Wood. Ind. Eng. Chem. Res. 2002, 41, 4201-4208.

(12) Cho, J.; Chu, S.; Dauenhauer, P. J.; Huber, G. W. Kinetics and reaction chemistry for slow pyrolysis of enzymatic hydrolysis lignin and organosolv extracted lignin derived from maplewood. Green Chem. 2012, 14, 428-439.

(13) Technical Association of the Pulp and Paper Industry (TAPPI). T222 om-88: Acid-Insoluble Lignin in Wood and Pulp; TAPPI: Atlanta, GA, 1988.

(14) Browning, B. L. Methods of Wood Chemistry; Interscience Publishers: New York, 1967.

(15) Carrier, M.; Joubert, J. E.; Danje, S.; Hugo, T.; Görgens, J.; Knoetze, J. H. Impact of the lignocellulosic material on fast pyrolysis yields and product quality. Bioresour. Technol. 2013, 150, 129-138.

(16) Gronli, M.; Antal, M. J.; Varhegyi, G. A Round-Robin Study of Cellulose Pyrolysis Kinetics by Thermogravimetry. Ind. Eng. Chem. Res. 1999, 38, 2238-2244.

(17) Burnham, A. K.; Braun, R. L. Global Kinetic Analysis of Complex Materials. Energy Fuels 1999, 13 (1), 1-22.

(18) Vyazovkin, S.; Burnham, A. K.; Criado, J. M.; Pérez-maqueda, L. A.; Popescu, C.; Sbirrazzuoli, N. ICTAC Kinetics Committee recommendations for performing kinetic computations on thermal analysis data. Thermochim. Acta 2011, 520, 1-19.

(19) Arnold, M.; Veress, G. E.; Paulik, J.; Paulik, F. A critical reflection upon the application of the Arrhenius model to nonisothermal thermogravimetric curves. Thermochim. Acta 1982, 52 (13), $67-81$

(20) Vyazovkin, S.; Wight, C. A. Isothermal and non-isothermal kinetics of thermally stimulated reactions of solids. Int. Rev. Phys. Chem. 1998, 17 (3), 407-433.

(21) Chen, H. X.; Liu, N. A.; Shu, L. F.; Zong, R. W. Smoothing and differentiation of thermogravimetric data of biomass materials. J. Therm. Anal. Calorim. 2004, 78, 1029-1041.

(22) Caballero, A.; Conesa, J. A. Mathematical considerations for non-isothermal kinetics in thermal decomposition. J. Anal. Appl. Pyrolysis 2005, 73, 85-100.

(23) Budrugeac, P. Theory and practice in the thermoanalytical kinetics of complex processes: Application for the isothermal and nonisothermal thermal degradation of HDPE. Thermochim. Acta 2010, 500 (1-2), 30-37.

(24) Vyazovkin, S. Modification of the Integral Isoconversional Method to Account for Variation in the Activation Energy. J. Comput. Chem. 2001, 22 (2), 178-183.

(25) Carrier, M.; Loppinet-Serani, A.; Denux, D.; Lasnier, J.-M.; Ham-Pichavant, F.; Cansell, F.; Aymonier, C. Thermogravimetric analysis as a new method to determine the lignocellulosic composition of biomass. Biomass Bioenergy 2011, 35 (1), 298-307.

(26) Haykiri-Acma, H.; Yaman, S.; Kucukbayrak, S. Effect of heating rate on the pyrolysis yields of rapeseed. Renewable Energy 2006, 31, 803-810.

(27) Ridout, A. J.; Carrier, M.; Görgens, J. Fast pyrolysis of low and high ash paper waste sludge: Influence of reactor temperature and pellet size. J. Anal. Appl. Pyrolysis 2015, 111, 64-75.
(28) Mamleev, V.; Bourbigot, S.; Le Bras, M.; Yvon, J. The facts and hypotheses relating to the phenomenological model of cellulose pyrolysis. J. Anal. Appl. Pyrolysis 2009, 84 (1), 1-17.

(29) Lochab, B.; Shukla, S.; Varma, I. K. Naturally occurring phenolic sources: monomers and polymers. RSC Adv. 2014, 4 (42), 21712.

(30) Di Blasi, C.; Lanzetta, M. Intrinsic kinetics of isothermal xylan degradation in inert atmosphere. J. Anal. Appl. Pyrolysis 1997, 40-41, 287-303.

(31) Várhegyi, G.; Antal, M. J.; Jakab, E.; Szabó, P. Kinetic modeling of biomass pyrolysis. J. Anal. Appl. Pyrolysis 1997, 42 (1), 73-87.

(32) Cai, J.; Wu, W.; Liu, R.; Huber, G. W. A distributed activation energy model for the pyrolysis of lignocellulosic biomass. Green Chem. 2013, 15 (5), 1331-1340.

(33) Várhegyi, G. Aims and methods in non-isothermal reaction kinetics. J. Anal. Appl. Pyrolysis 2007, 79 (1-2), 278-288.

(34) Antal, M. J.; Varhegyi, G. Cellulose Pyrolysis Kinetics: The Current State of Knowledge. Ind. Eng. Chem. Res. 1995, 34 (3), 703717.

(35) Sharma, R. K.; Wooten, J. B.; Baliga, V. L.; Lin, X.; Geoffrey Chan, W.; Hajaligol, M. R. Characterization of chars from pyrolysis of lignin. Fuel 2004, 83 (11-12), 1469-1482.

(36) Kumar, R.; Mago, G.; Balan, V.; Wyman, C. E. Physical and chemical characterizations of corn stover and poplar solids resulting from leading pretreatment technologies. Bioresour. Technol. 2009, 100 (17), 3948-3962.

(37) Pastorova, I.; Botto, R. E.; Arisz, P. W.; Boon, J. J. Cellulose char structure: A combined analytical Py-GC-MS, FTIR, and NMR study. Carbohydr. Res. 1994, 262 (1), 27-47.

(38) Scheirs, J.; Camino, G.; Tumiatti, W. Overview of water evolution during the thermal degradation of cellulose. Eur. Polym. J. 2001, 37 (5), 933-942.

(39) Du, X.; Gellerstedt, G.; Li, J. Universal fractionation of lignincarbohydrate complexes (LCCs) from lignocellulosic biomass: an example using spruce wood. Plant J. 2013, 74 (2), 328-338.

(40) Di Blasi, C. Modeling chemical and physical processes of wood and biomass pyrolysis. Prog. Energy Combust. Sci. 2008, 34 (1), 47-90.

(41) Prakash, N.; Karunanithi, T. Kinetic Modeling in Biomass Pyrolysis-A Review. J. Appl. Sci. Res. 2008, 4 (12), 1627-1636. 